\title{
Solo Single-Incision Laparoscopic Appendectomy versus Conventional Single-Incision Laparoscopic Appendectomy
}

\author{
Min-Su Park, M.D., Ph.D. \\ Department of Surgery, Kyung Hee University Hospital, Kyung Hee University School of Medicine, Seoul, Korea
}

Corresponding author

Min-Su Park

Department of Surgery, Kyung Hee University Hospital, Kyung Hee University School of Medicine, 26 Kyungheedae-ro, Dongdaemun-gu, Seoul 02447, Korea

Tel: +82-2-958-8241, Fax: +82-2-966-9366, E-mail: ikireida@hanmail.net

ORCID: http://orcid.org/0000-0002-0707-2969

This is an Open Access article distributed under the terms of the Creative Commons Attribution Non-Commercial License (http:// creativecommons.org/licenses/by-nc/4.0/) which permits unrestricted non-commercial use, distribution, and reproduction in any medium, provided the original work is properly cited.
Copyright $\odot 2018$ The Journal of Minimally Invasive Surgery. All rights reserved.
With improvement of surgical techniques and development of laparoscopic devices, solo surgery has been introduced. Solo surgery, which refers to performing surgical procedures without surgical assistants except for a scrub nurse, is a surgical approach that can help the operator to control the visual field fully while improving eye-hand coordination. ${ }^{1-3}$ With these advantages, applications of solo surgery have expanded from minor resection to more complicated cases, including major colorectal and hepatic resections. Recently, single incision laparoscopic surgery has been performed in fields requiring minimal access surgery, which has resulted in clear-cut benefits in terms of cosmetic aspects, reduced bleeding and wound morbidity. Because of some disadvantages such as expensive instruments, longer operation time, technical difficulties and longer learning curve, this approach is not widely practiced. ${ }^{4}$ However, the technical difficulties have been overcome by solo surgery using mechanically adjustable instruments.

This study compared the outcomes of conventional single incision laparoscopic appendectomy (C-SILA) and solo SILA (S-SILA) based on retrospective analysis of a single-center's experience. Previous studies reported that the S-SILA provided a wide space for a surgeon and direct control of laparoscopic vision. Moreover, this approach has been shown to reduce costs. ${ }^{3,5}$ It should be noted that this study is limited in that it was a retrospective study with a small number of patients and selection bias. However, the author's presented valuable data with a specific focus on S-SILA performed by residents. In this study, S-SILA economized staff numbers and thus reduced hospital costs without lengthening the operating time. Moreover, the authors emphasized that surgical residents can perform S-SILA without any intervention from staff. This is a meaningful study that will serve as a basis for the training and education of surgical residents. It is expected that a collection of small retrospective studies such as this one will provide good evidence of the benefits of solo surgery.

\section{REFERENCES}

1) Jaspers JE, Breedveld P, Herder JL, Grimbergen CA. Camera and instrument holders and their clinical value in minimally invasive surgery. Surg Laparosc Endosc Percutan Tech 2004;14:145-152.

2) Arezzo A, Ulmer F, Weiss O, Schurr MO, Hamad M, Buess GF. Experimental trial on solo surgery for minimally invasive therapy: comparison of different systems in a phantom model. Surg Endosc 2000;14:955-959.

3) Kim SJ, Choi BJ, Lee SC. Novel approach of single-port lapa- 
roscopic appendectomy as a solo surgery: A prospective cohort study. Int J Surg 2015;21:1-7.

4) Koca D, Yildiz S, Soyupek F, et al. Physical and mental workload in single-incision laparoscopic surgery and conventional laparos- copy. Surg Innov 2015;22:294-302.

5) Kim SJ, Choi BJ, Jeong WJ, Lee SC. The feasibility of single-port laparoscopic appendectomy using a solo approach: a comparative study. Ann Surg Treat Res 2016;90:164-170. 